\title{
Cognitive distortions in epilepsy patients: metacognitive functions, automatic thoughts, and dysfunctional attitudes
}

\author{
Filiz Ozsoy ${ }^{1}$, Irem Tasci ${ }^{\circledR}$ \\ 'Tokat State Hospital, Department of Psychiatry, Tokat - Turkey \\ ${ }^{2}$ Malatya Training and Research Hospital, Department of Neurology, Malatya - Turkey
}

\begin{abstract}
Objective: The association of psychiatric disorders with epilepsy was shown in many publications, but there have been very few studies dealing with cognitive distortions in epilepsy patients. In our study, we aimed to investigate the metacognitive systems, dysfunctional attitudes, and automatic thoughts of epilepsy patients.

Method: Sixty patients diagnosed with epilepsy based on anamnesis and electroencephalographic examination and 50 healthy controls were included in the study. The sociodemographic data form, Beck Anxiety Inventory (BAI), Beck Depression Inventory (BDI), Automatic Thoughts Questionnaire (ATQ), Dysfunctional Attitudes Scale (DAS), and Metacognition Questionnaire-30 (MCQ) were administered to all participants.

Results: BAI and BDI scores were significantly higher in the epilepsy group compared to the control group $(p=0.001, p<0.05$, respectively). The "uncontrollability-danger" and "cognitive awareness" subscale scores and the total score of MCQ in the epilepsy group were also higher than in the control group $(p=0.001, p<0.05, p=0.001$, respectively). The ATQ total score was found to be significantly higher in the epilepsy group compared to the control group $(p=0.001)$.

Conclusion: Based on the findings from the present study, in order to understand and support epilepsy patients better and provide diagnosis/treatment for psychiatric diseases that may be overlooked, it is recommended that clinical neurologists and psychiatrists evaluate patients in cooperation.
\end{abstract}

Keywords: Cognitive dissonances, dysfunctional attitudes, epilepsy, metacognition

\section{INTRODUCTION}

Epilepsy is a chronic disease whose association with psychiatric disorders has been shown in many studies. Anxiety and depressive disorders could be observed in up to $30 \%$ of epilepsy patients (1). The presence of a comorbid psychiatric disease in epilepsy patients negatively affects the frequency and severity of seizures, the course of the disease, the patients' quality of life, and their response to treatment (2).

It has been mentioned that dysfunctional metacognitive mechanisms play various roles in many psychiatric diseases (3). The metacognitive system is a higher-order system that allows a person to recognize events in his/her own mind and to manage them in a volitional manner. Metacognition has a very important

How to cite this article: Ozsoy F, Tasci I. Cognitive distortions in epilepsy patients: metacognitive functions, automatic thoughts, and dysfunctional attitudes. Dusunen Adam The Journal of Psychiatry and Neurological Sciences 2020;33:261-269.

Correspondence: Filiz Ozsoy, Yeni District, Tokat State Hospital, 60100 Center, Tokat - Turkey 
role in the functional and adaptational operation of a person's cognitive processes. Any deterioration in this system is thought to lead to the onset and continuation of many psychopathologies (4).

Dysfunctional attitudes and automatic thoughts, on the other hand, are defined as distorted thoughts that directly affect a person's ways of behaviors and mental health (5). Dysfunctional attitudes are negative beliefs towards oneself, other people, and the world, and are created by an individual communicating with other people. They are characteristically strict, permanent, and generalized (6). Automatic thoughts, on the other hand, are the first reactions to occur spontaneously in the mind of a person as quickly as a reflex, without being noticed. When a person is confronted with a particular situation, some underlying beliefs affect his or her perceptions of the event and lead to automatic thoughts. These thoughts change the emotional responses, and the emotional responses in turn change the thinking style, which eventually determines the person's response to the event involved (7).

Many studies in the literature found that the prevalence of psychiatric disorders is higher in epilepsy patients than in the normal population. Anxiety and mood disorders, attention deficit, hyperactivity, psychotic and personality disorders were among the most commonly reported comorbid psychiatric diseases in epilepsy $(8,9)$. There is a limited number of studies examining metacognitive mechanisms in epilepsy patients $(10,11)$. However, no studies were encountered that evaluate the metacognition system, automatic thoughts, and dysfunctional attitudes together. The aim of the present study was to reveal dysfunctional metacognitions in epilepsy patients. Secondly, we aimed to investigate patients' cognitive schemas, negative automatic thoughts, and dysfunctional attitudes. Finally, we also aimed to evaluate the patients' anxiety and depression levels. Our first assumption was that epilepsy patients are affected by dysfunctional metacognitions in certain areas. Our second assumption was that patients have negative cognitive schemas regarding themselves, their environment, and the world. Finally, it was assumed that the levels of depression and anxiety are high in epilepsy patients. Dysfunctional metacognitions and negative cognitive schemas are presumed to increase psychiatric comorbidity rates in epilepsy patients, which in turn could aggravate the disease and impair compliance with the treatment. In this context, it was thought that the epilepsy patients should be jointly evaluated by neurologists and psychiatrists. Thus, the patient's treatment could be more beneficial by increasing his or her compliance, reducing the negative effects of the disease on the individual, and helping with reintegration of the patient into society.

\section{METHOD}

\section{Participants and Procedure}

Our study was carried out in the neurology outpatient clinic of Malatya Training and Research Hospital in the period from June 1 to December 31, 2018. Approximately 200 patients diagnosed with focal and generalized epilepsy based on anamneses and electroencephalography (EEG) findings and receiving antiepileptic treatment while being monitored with regular follow-ups were interviewed. The study was approved by Tokat Gaziosmanpasa University's local non-invasive ethics committee (Date: November ,8, 2017 under no: 83116987-433). The study procedures were implemented in accordance with the Helsinki Declaration.

Inclusion criteria were voluntary participation, age in the range of 18-55 years, at least one year's diagnosis of epilepsy, monitoring by neurology physicians, and literacy. Exclusion criteria, on the other hand, were diagnoses of mental retardation, neurodegenerative diseases, chronic diseases, a diagnosis of refractory epilepsy, with a related history of surgical intervention, poor general condition, and unwillingness to participate. Individuals with psychiatric illness and current or past alcohol or substance abuse requiring treatment were not included in the study. The healthy control group was selected from people with matching demographic characteristics such as age, gender, and education level who did not have current or previous incidences of fainting. Individuals with psychiatric diseases currently needing treatment or being documented in the medical records, with psychiatric medication use, and with alcohol/substance abuse were not included in the healthy control group.

A total of 60 patients with epilepsy treated for at least one year and a control group consisting of 50 healthy individuals participated in the study. The mean age of the clinical and nonclinical subjects was 24.79 (standard deviation=7.98) years. More than half of the overall sample members were male (56.4\%) and 78.2\% of the participants were single. None of the participants had a diagnosed psychiatric disease or any additional medical disease currently or previously. The 
Table 1: Sociodemographic characteristics of the participants

\begin{tabular}{|c|c|c|c|c|c|c|c|}
\hline \multirow[t]{2}{*}{ Variables } & \multicolumn{2}{|c|}{ Healthy control group } & \multicolumn{2}{|c|}{ Epilepsy patient group } & \multirow[b]{2}{*}{$\chi^{2}$} & \multirow[b]{2}{*}{ df } & \multirow[b]{2}{*}{$\mathbf{p}$} \\
\hline & $n=50$ & $\%$ & $n=60$ & $\%$ & & & \\
\hline \multicolumn{8}{|l|}{ Gender } \\
\hline Female & 20 & 40 & 28 & 46.7 & 0.493 & 1 & 0.483 \\
\hline Male & 30 & 60 & 32 & 53.3 & & & \\
\hline \multicolumn{8}{|l|}{ Marital status } \\
\hline Married & 8 & 16 & 16 & 26.7 & 1.819 & 1 & 0.177 \\
\hline Single & 42 & 84 & 44 & 73.3 & & & \\
\hline \multicolumn{8}{|l|}{ Place of residence } \\
\hline City center & 35 & 70 & 50 & 83.3 & 3.273 & 2 & 0.195 \\
\hline District & 10 & 20 & 8 & 13.3 & & & \\
\hline Village & 5 & 10 & 2 & 3.3 & & & \\
\hline \multicolumn{8}{|l|}{ Educational status } \\
\hline Literate & 2 & 4 & 0 & 0.0 & 9.378 & 3 & 0.025 \\
\hline Primary school graduate & 1 & 2 & 9 & 15.0 & & & \\
\hline High school graduate & 17 & 34 & 25 & 41.7 & & & \\
\hline Postgraduate & 30 & 60 & 26 & 43.3 & & & \\
\hline \multicolumn{8}{|l|}{ Employment status } \\
\hline Fulltime job & 4 & 8 & 13 & 21.7 & 14.370 & 5 & 0.013 \\
\hline Part-time job & 1 & 2 & 5 & 8.3 & & & \\
\hline Housewife & 11 & 22 & 12 & 20 & & & \\
\hline Student & 31 & 62 & 23 & 38.3 & & & \\
\hline Retired & 1 & 2 & 7 & 11.7 & & & \\
\hline Unemployed & 2 & 4 & 0 & 0 & & & \\
\hline \multicolumn{8}{|l|}{ Socioeconomic status } \\
\hline Low & 21 & 42 & 16 & 26.7 & 2.894 & 2 & 0.235 \\
\hline Moderate & 24 & 48 & 37 & 61.7 & & & \\
\hline High & 5 & 10 & 7 & 11.7 & & & \\
\hline Seizure type & & & & & - & & - \\
\hline Generalized & - & & 24 & 40.0 & & & \\
\hline Focal & - & & 10 & 16.7 & & & \\
\hline Generalized secondary to focal seizure & - & & 26 & 43.3 & & & \\
\hline
\end{tabular}

None of the participants had a diagnosed psychiatric disease or any additional medical disease currently or previously. Data shown as frequency, percentage (\%). Chi-square test was used

characteristics of the sample are presented in Table 1. The patient group was divided into three sub-groups based on patients' descriptions of seizure during the anamnesis, EEG findings, and the antiepileptic drugs they used. Twenty-four persons were considered to have primary generalized epilepsy, 10 individuals focal epilepsy, and 26 patients generalized epilepsy secondary to focal epilepsy. However, since differences in the mean scores of the epilepsy sub-groups were not statistically significant for any of the scales used, the sub-groups were evaluated together.

\section{Measures}

All participants signed a written consent form. Sociodemographic data form, Beck Depression Inventory (BDI), Beck Anxiety Inventory (BAI), Automatic Thoughts Scale (ATQ), Dysfunctional Attitudes Scale (DAS) and Metacognition Questionnaire-30 (MCQ) were administered to all participants.

Sociodemographic Data Form: Prepared by the researchers, this form included questions about demographic data such as age, marital status, educational status, working and economic status, as 
well as some clinical information regarding the time period since being diagnosed with epilepsy, and whether they received psychiatric treatment.

Beck Depression Inventory (BDI): This self-report scale was developed by Beck et al. (12) and adapted into Turkish by Hisli (13). It is used for the evaluation of depression risk and the level and severity of depressive symptoms. Each item is given a score of 0-3; the total score ranges from $0-63$. Higher scores indicate higher depression severity. In Turkish reliability studies, a Cronbach's a value of 0.80 was calculated for the inventory $(12,13)$.

Beck Anxiety Inventory (BAI): This form was developed by Beck et al. (14) and was adapted into Turkish by Ulusoy et al. (15). It is used to measure the frequency of anxiety symptoms. This self-reporting scale consists of a total of 21 questions. Each item is given a score between 0 and 3 . Higher total scores indicate higher anxiety experienced by the subject. The maximum score is 63 . The study showing the validity of the Turkish version reported an internal consistency score with Cronbach's a of 0.93 .

Metacognition Questionnaire (MCQ-30): This is a Likert-type self-reporting scale developed by Wells and Cartwright-Hatton (4). Each item is scored between 1 and 4. It consists of five subscales, which are conceptually different, but in relation with each other: "Positive beliefs," "cognitive confidence," "uncontrollability-danger," "cognitive awareness," and "control needs." The scores of the scale range from 30 to 120 , and higher scores indicate pathologically increased metacognitive activity. In a validity and reliability study for the Turkish version by Tosun and Irak (16), correlations between all items were significant. Correlation coefficients between the items of the questionnaire varied from 0.40 to 0.94 , while those between the subscales varied from 0.70 to 0.85 . In reliability studies for the Turkish version, a total Cronbach's a value of 0.86 was calculated for the inventory.

Automated Thoughts Questionnaire (ATQ): This instrument was developed by Hollan and Kendal (17). Each item is scored between 1 and 5, and there is a total of 30 items. This is a Likert-type self-reporting scale. It has five subscales: "self-negative feelings and thoughts," "confusion-evasion fantasies," "personal incompatibility and change requests," "loneliness-isolation," and "despair." In an adaptation study for Turkish by Savasir and Sahin (18), the internal consistency coefficient was 0.93 , and correlations between the items ranged from 0.36 to 0.69 .
Dysfunctional Attitudes Scale (DAS): Developed by Weissman and Beck (19), it was adapted into Turkish by Sahin and Sahin (20). This self-reported scale is used to determine dysfunctional attitudes related to depression. It is a 7-point Likert-type scale consisting of 40 items. Subscales "perfectionist attitude," "variable attitude," "need for approval," and "independent attitude" and a total score are calculated in the scale. Higher scores indicate a higher frequency of dysfunctional attitudes. In the validity and reliability study for the Turkish version, item-total correlation was 0.34 , and Cronbach's a value was 0.79 .

\section{Statistical Analyses}

Data were evaluated using SPSS version 19 (Statistical Package for Social Sciences for Windows 19). Before the scale scores were calculated, descriptive statistical analyses and reliability analyses of the measures were performed and Cronbach's a reliabilities of the scales were estimated. Normal distribution was controlled using Shapiro-Wilk (SW) test. Qualitative variables were presented as numbers with mean and standard deviation $($ Mean $\pm S D)$ and percentages. The qualitative variables were evaluated using chi-square tests. For the statistical analysis of normally distributed data, independent samples t-test was used; results were reported with mean and standard deviation. A multivariate logistic regression analysis was performed to assess the effect of the following independent variables on the presence of the dependent variable: age, gender, marital status, settlement, education, employment, and socioeconomic status. Relations between data within groups were examined using Pearson correlation analysis. Beta coefficient $(\beta)$, odds ratio (OR), and $95 \%$ confidence interval (CI) were computed for each independent variable. Mean values, standard deviations of the scores, and correlation were analyzed and it was noted that the p-value was less than 0.05 , indicating an acceptable level of significance.

\section{RESULTS}

\section{Sample Characteristics}

Using the chi-square test, we found that there was no difference between the epilepsy patient group and the healthy control group for the demographic variables studied except for educational level and working status. The mean age was 26.68 (standard deviation $(\mathrm{SD})=9.76$ ) in the epilepsy group and $26.62(\mathrm{SD}=5.19)$ in the healthy control group ( $\mathrm{p}=0.521)$. Epilepsy patients had lower levels of education than healthy adults $\left(\chi^{2}=9.378\right.$, 
$\mathrm{p}=0.025)$. There was a significant difference between groups regarding employment status $\left(\chi^{2}=14.370\right.$, $\mathrm{p}=0.013)$. The patients' disease period varied between 1 and 30 years (mean $=8.17, S D=7.62)$. Participants' characteristics are presented in Table 1.

\section{Correlation Analysis}

Pearson correlation analysis evaluating the relation between BDI score and the "uncontrollability-danger" subscale score of MCQ found a moderate and positive correlation $(\mathrm{r}=0.575, \mathrm{p}<0.05)$. Similarly, BAI showed a moderate positive correlation with the "uncontrollability-danger" subscale score of MCQ $(\mathrm{r}=0.573, \mathrm{p}<0.05)$. The "uncontrollability-danger" subscale score of MCQ revealed a moderate positive correlation with the ATQ subscales "self-negative feelings and thoughts," "confusion-evasion fantasies," "loneliness-isolation," and "despair" $(\mathrm{r}=0.572, \mathrm{p}<0.05$; $\mathrm{r}=0.484, \mathrm{p}<0.05 ; \mathrm{r}=0.432, \mathrm{p}<0.05 ; \mathrm{r}=0.496, \mathrm{p}<0.05$; respectively). Correlation analysis findings are shown in Table 2.

\section{Cronbach's a Values Calculated for the Study}

Before calculating the scores of the scales administered to the participants, Cronbach's a reliability values for the study results were worked out. Cronbach's a values calculated for the MCQ were 0.883 and 0.669 for the control group and epilepsy patients, respectively. The total Cronbach's a value was 0.699. Cronbach's a values in the ATQ were 0.925 and 0.889 for the control group and epilepsy patients, respectively. The total Cronbach's a value calculated for our study was 0.910 . Cronbach's a values for the DAS were 0.452 and 0.694 for the control group and epilepsy patients, respectively. The total Cronbach's a value was calculated as 0.608 .

\section{Scale Scores}

The BDI score in the epilepsy group was significantly higher than in the control group $(\mathrm{f}=18.662, \mathrm{t}=5.508$, $\mathrm{p}<0.05$ ). Similarly, the BAI score was significantly higher in the epilepsy group compared to the control group $(\mathrm{f}=16.608, \mathrm{t}=3.567, \mathrm{p}=0.001)$. The "uncontrollability-danger" subscale score of the MCQ was significantly higher in the epilepsy group compared to the control group $(\mathrm{f}=0.074, \mathrm{t}=3.183, \mathrm{p}=0.002)$. The "cognitive awareness" subscale score of the MCQ was significantly higher in the epilepsy group ( $\mathrm{f}=1.033$, $\mathrm{t}=3.747, \mathrm{p}<0.05$ ). All subscale scores of the ATQ were significantly higher in the epilepsy group than in the control group. Only the "need for approval" subscale of the DAS was significantly higher in the epilepsy group compared to the control group $(\mathrm{f}=4.230, \mathrm{t}=2.000$, $\mathrm{p}=0.048$ ) (Table 3).

A multivariate logistic regression analysis revealed that being a housewife or a student were significant predictors for epilepsy $(\beta=-5.369, p=0.014 ; \beta=-4.074$, $\mathrm{p}=0.028$; respectively). Similarly, the BDI score was a

Table 2: Pearson correlation analysis of epilepsy group

\begin{tabular}{lcccccccc} 
& MCQ 1 & MCQ 2 & MCQ 3 & MCQ 4 & MCQ 5 & MCQ-total & BDI & BAI \\
\hline ATQ & & & & & & & & \\
Negative self & 0.005 & 0.050 & $0.572^{*}$ & $0.372^{*}$ & 0.097 & $0.476^{*}$ & $0.619^{*}$ & $0.439^{*}$ \\
$\quad$ Confusion/flight of ideas & -0.032 & -0.060 & $0.484^{*}$ & $0.327^{*}$ & 0.119 & $0.373^{*}$ & $0.430^{*}$ & $0.414^{*}$ \\
Self-discrepancy & -0.113 & -0.050 & $0.374^{*}$ & 0.245 & 0.086 & $0.290^{*}$ & $0.481^{*}$ & $0.480^{*}$ \\
Loneliness/isolation & -0.158 & 0.027 & $0.432^{*}$ & $0.283^{*}$ & -0.040 & $0.261^{*}$ & $0.525^{*}$ & $0.432^{*}$ \\
Abandonment/despair & -0.057 & 0.007 & $0.496^{*}$ & $0.309^{*}$ & 0.155 & $0.455^{*}$ & $0.499^{*}$ & $0.263^{*}$ \\
Total score & -0.056 & 0.000 & $0.558^{*}$ & $0.360^{*}$ & 0.097 & $0.435^{*}$ & $0.609^{*}$ & $0.476^{*}$ \\
DAS & & & & & & & \\
Perfectionist attitude & 0.090 & $0.438^{*}$ & $0.277^{*}$ & 0.086 & 0.086 & $0.281^{*}$ & 0.090 & -0.048 \\
Variable attitude & 0.064 & -0.251 & -0.245 & -0.176 & -0.176 & -0.212 & 0.064 & -0.127 \\
Need for approval & 0.083 & $0.316^{*}$ & $0.274^{*}$ & 0.090 & 0.090 & $0.263^{*}$ & 0.083 & -0.099 \\
Independent attitude & 0.060 & 0.028 & -0.180 & -0.119 & -0.119 & -0.134 & 0.060 & -0.074 \\
Total score & 0.102 & $0.369^{*}$ & 0.230 & 0.051 & 0.051 & 0.233 & 0.102 & -0.067 \\
BDI & 0.117 & 0.256 & $0.575^{*}$ & $0.381^{*}$ & 0.167 & $0.536^{*}$ & -
\end{tabular}


Table 3: Comparison of scale scores between groups

\begin{tabular}{|c|c|c|c|c|c|c|c|}
\hline & \multicolumn{2}{|c|}{ Healthy control group } & \multicolumn{2}{|c|}{ Epilepsy patient group } & \multirow[b]{2}{*}{ f } & \multirow[b]{2}{*}{$t(d f=108)$} & \multirow[b]{2}{*}{$\mathbf{p}$} \\
\hline & Mean & SD & Mean & SD & & & \\
\hline Beck Depression Inventory & 5.4 & 5.3 & 13.0 & 8.4 & 18.662 & 5.508 & $<0.05$ \\
\hline Beck Anxiety Inventory & 6.6 & 7.6 & 13.9 & 12.4 & 16.608 & 3.567 & 0.001 \\
\hline \multicolumn{8}{|l|}{ Metacognitive Questionnaire } \\
\hline Positive belief & 12.9 & 4.7 & 12.6 & 4.0 & 1.430 & 0.284 & 0.777 \\
\hline Cognitive confidence & 11.1 & 4.6 & 18.0 & 31.0 & 1.253 & 1.563 & 0.121 \\
\hline Uncontrollability-danger & 13.9 & 5.6 & 17.2 & 5.2 & 0.074 & 3.183 & 0.002 \\
\hline Cognitive awareness & 13.4 & 4.3 & 16.5 & 4.3 & 1.033 & 3.747 & $<0.05$ \\
\hline The need to control the thoughts & 11.0 & 3.6 & 12.2 & 4.0 & 0.176 & 1.607 & 0.111 \\
\hline Total score & 62.4 & 19.1 & 73.1 & 13.8 & 2.893 & 3.389 & 0.001 \\
\hline \multicolumn{8}{|l|}{ Automatic Thoughts Questionnaire } \\
\hline Negative self & 16.7 & 8.4 & 22.3 & 10.7 & 5.291 & 2.988 & 0.003 \\
\hline Confusion/flight of ideas & 10.4 & 4.4 & 13.7 & 6.0 & 6.534 & 3.216 & 0.002 \\
\hline Self-discrepancy & 6.2 & 3.2 & 9.1 & 4.1 & 5.416 & 4.118 & $<0.05$ \\
\hline Loneliness/isolation & 7.5 & 3.7 & 10.4 & 4.4 & 3.039 & 3.565 & 0.001 \\
\hline Abandonment/despair & 7.4 & 3.7 & 10.1 & 5.8 & 7.305 & 2.792 & 0.006 \\
\hline Total score & 48.8 & 22.2 & 65.6 & 27.0 & 3.864 & 3.579 & 0.001 \\
\hline \multicolumn{8}{|l|}{ Dysfunctional Attitude Scale } \\
\hline Perfectionist attitude & 51.8 & 18.4 & 54.1 & 20.2 & 0.539 & 0.624 & 0.534 \\
\hline Variable attitude & 15.7 & 5.7 & 15.5 & 3.8 & 9.201 & 0.232 & 0.817 \\
\hline Need for approval & 35.8 & 11.4 & 40.9 & 14.9 & 4.230 & 2.000 & 0.048 \\
\hline Independent attitude & 19.8 & 8.6 & 19.3 & 4.7 & 18.668 & 0.359 & 0.720 \\
\hline Total score & 122.0 & 24.6 & 130.2 & 34.7 & 5.617 & 1.392 & 0.167 \\
\hline
\end{tabular}

Data are shown as mean \pm standard deviation. Independent samples $t$ test was used

significant predictor for epilepsy $(\beta=0.245, \mathrm{p}=0.001)$ (Table 4).

\section{DISCUSSION}

Psychiatric symptoms or psychiatric disorders are frequently observed in epilepsy patients. Psychiatric illness comorbidity can affect the course of the disease (2-5). In the present study, metacognitive functions, dysfunctional attitudes, and automatic thoughts that could play a role in psychiatric comorbidities of epilepsy patients were evaluated. In our results, anxiety and depression scores of patients with epilepsy were significantly higher than in the control group. In the MCQ, "uncontrollability and danger" and "cognitive awareness" subscales and total score were higher compared to the control group. All subscales of ATQ and only the "need for approval" subscale of DAS were significantly higher in the patient group than in the control group. No other study in the literature has so far evaluated epilepsy patients using these scales together. Our results showed that scores of both depression and anxiety scales in the patient group were considerably higher than in the control group. This finding was consistent with reports from many studies in the literature $(1,2)$. No history of psychiatric treatment was found in epilepsy patients, a finding that was somewhat expected as regular medical treatment is taken for epilepsy and because epilepsy is a disorder that can affect many areas such as family, social and working life.

Only a limited number of studies evaluating epilepsy patients with the MCQ were found in the literature. In one of them, the five-factor structure of MCQ was shown to have internal consistency in epilepsy patients. In addition, metacognitive processes were reported to be effective determinants of anxiety and depression (10). In another study, the effects of metacognitive structure on the perception of disease were investigated. Strong relationships between the metacognitive model and the anxiety and depression levels of epilepsy patients were emphasized (11). The MCQ subscales 
Table 4: The effect of variables on epilepsy disease according to logistic regression model

For odds ratio

\begin{tabular}{|c|c|c|c|c|c|c|}
\hline \multirow[b]{2}{*}{ Covariates } & \multirow[b]{2}{*}{ Beta } & \multirow[b]{2}{*}{ SE } & \multirow[b]{2}{*}{$\mathbf{p}$} & \multirow[b]{2}{*}{ Odds Ratio } & \multicolumn{2}{|c|}{$\mathbf{9 5 \%}$ confidence interval } \\
\hline & & & & & Lower limit & Upper limit \\
\hline Age & 0.049 & 0.060 & 0.413 & 1.050 & 0.934 & 1.181 \\
\hline Gender & -1.279 & 0.711 & 0.072 & 0.278 & 0.069 & 1.121 \\
\hline Marital status & -0.079 & 1.134 & 0.944 & 0.924 & 0.100 & 8.526 \\
\hline \multicolumn{7}{|l|}{ Place of residence } \\
\hline District & -0.359 & 0.902 & 0.690 & 0.698 & 0.119 & 4.089 \\
\hline Village & -1.231 & 1.425 & 0.388 & 0.292 & 0.018 & 4.771 \\
\hline \multicolumn{7}{|l|}{ Educational status } \\
\hline Primary school & 1.797 & 0.654 & 0.976 & 6.032 & 0.054 & 12.430 \\
\hline High school & 1.729 & 0.635 & 0.987 & 5.635 & 0.067 & 11.248 \\
\hline Postgraduate & 1.997 & 0.734 & 0.965 & 7.367 & 0.026 & 13.060 \\
\hline \multicolumn{7}{|l|}{ Employment status } \\
\hline Part-time job & -1.616 & 2.198 & 0.462 & 0.199 & 0.003 & 14.767 \\
\hline Housewife & -5.369 & 2.184 & $0.014^{*}$ & 0.005 & 0.000 & 0.337 \\
\hline Student & -4.074 & 1.857 & $0.028^{*}$ & 0.017 & 0.000 & 0.648 \\
\hline Retired & -3.206 & 2.224 & 0.149 & 0.041 & 0.001 & 3.165 \\
\hline Unemployed & -6.591 & 3.568 & 0.989 & 0.001 & 0.000 & 5.645 \\
\hline \multicolumn{7}{|c|}{ Socioeconomic status } \\
\hline Moderate & 0.076 & 0.656 & 0.908 & 1.078 & 0.298 & 3.903 \\
\hline High & -2.576 & 1.694 & 0.128 & 0.076 & 0.003 & 2.104 \\
\hline BDI & 0.245 & 0.073 & $0.001^{*}$ & 1.278 & 1.107 & 1.475 \\
\hline BAI & -0.050 & 0.041 & 0.216 & 0.951 & 0.878 & 1.030 \\
\hline MCQ & 0.000 & 0.023 & 0.993 & 1.000 & 0.956 & 1.045 \\
\hline ATQ & 0.014 & 0.015 & 0.341 & 1.014 & 0.985 & 1.044 \\
\hline DAS & -0.024 & 0.014 & 0.080 & 0.976 & 0.950 & 1.003 \\
\hline
\end{tabular}

Abbreviations used in the table: SE: Standard error, ATQ: Automatic Thoughts Questionnaire, DAS: Dysfunctional Attitude Scale, BDI: Beck Depression Inventory, BAI: Beck Anxiety Inventory, MCQ: Metacognition Questionnaire. Reference categories: Female gender, marital status married, city center as place of residence, literate for educational status, fulltime job for employment status, low for socioeconomic status. ${ }^{*} \mathrm{p}<0.05$

"uncontrollability and danger" and "cognitive awareness" and total scores were significantly higher in epilepsy patients compared to the control group. The "uncontrollability and danger" subscale is interpreted to mean that the person needs to control his or her concerns to stay safe or that the concern cannot be controlled (16). Studies in the literature emphasized strong associations of the "uncontrollability and danger" and "cognitive confidence" subscales especially with depression and anxiety scores. Weaker relationships were reported for other subscales (11). In our results, the "uncontrollability and danger" subscale had moderate positive correlations with both depression and anxiety scales. In many studies, scores of this subscale were significantly higher in depressive disorder patients. The obtained results were attributed to depressive disorder patients' future pessimism, exaggeration and generalization of minor mishaps, and negative thoughts about themselves and their future (21). Since the depression and anxiety scores of the epilepsy patients are high and their quality of life is due to the nature of the disease and medical treatments received $(22,23)$, epilepsy patients' pessimistic, negative thoughts about themselves and their future, as in depressive disorder patients, seemed an expected outcome.

The "cognitive awareness" subscale, on the other hand, is interpreted as individuals dealing with thoughts in their mind and continuously reviewing and monitoring their opinions (16). In a study using the depression model for metacognition in epilepsy patients, no significant difference was found for this 
subscale, while a weak relationship was found with depression scores (11). In many studies with depressive disorder patients, no significant difference was found for this subscale (21). In patients with obsessive-compulsive disorder, "cognitive awareness" was linked with obsessions, which was in turn associated with a sense of responsibility and perfectionism (24). In our results, the score of this subscale was high and was weakly associated with depression scores. Although this finding could be attributed to the anxiety experienced by the patients, no significant increase was found for this subscale in every anxiety-related disorder. However, it was generally shown to be associated with anxiety scores $(21,25)$.

No other studies evaluating ATQ and DAS in epileptic patients were found. In our results, scores of all ATQ subscales were significantly higher in the patient group compared to the control group. All subscales of the ATQ were strongly correlated with depression and anxiety scores. In a general sense, most of ATQ subscales are related to depression and could be interpreted as patients' negative thoughts about themselves and the world, as the idea that they need to change but do not have the energy to do so, and as the feeling that they are all alone in life and should give up everything $(19,20)$. It was shown that automatic thoughts could predict the depression of a person by about 33\% (26). In multidimensional logistic regression analysis, with high depression scores of epilepsy patients, which have considerable effects on the disease, observing patients' negative automatic thoughts about their future and themselves was an expected outcome.

For DAS, only the subscale "need for approval," which is interpreted to mean that in order to be loved and to be a valued person one needs to be approved by other people, was significant. Dysfunctional attitudes were generally examined in depressive disorder patients. Even sub-threshold depression scores were found to be associated with dysfunctional cognitive schemas (27). Women with postpartum depression were reported to have dysfunctional cognitive attitudes, which were mentioned as being responsible for more severe depression (28). Obese individuals who were not diagnosed with depressive disorder were found to have a more dysfunctional schema than the healthy control group (29). In our results, DAS showed no correlation with depression or anxiety scales. Only some subscales of MCQ were found to be associated with "cognitive confidence" and "uncontrollability and danger." This finding could be due to the low reliability of the scale calculated or the high scores of the control group in the present study.

Our results should be evaluated while considering some limitations. These limitations are related to the cross-sectional nature of the study, the relatively low number of participants, self-completing of the questionnaires by the patients, and not using Structured Clinical Interview for DSM-5 (SCID-V) for our patients. These facts limit the generalizability and interpretation of the results. Further research with larger sample groups is required for a better generalization and effective use of our findings.

In epilepsy patients, whose lives are affected by the disease in many aspects, psychiatric co-morbidity is known to be high. Thus, we planned our study to evaluate the cognitive schemas of these patients. According to the results we obtained, patients had higher depression and anxiety levels, a higher level of dysfunctional metacognition in certain subscales and a higher level of automatic thoughts which are presumed to increase the depression. Based on these differences, in order to understand and help epilepsy patients better, it is recommended that clinical neurologists and psychiatrists should evaluate the patients together.

\begin{tabular}{|c|c|c|}
\hline \multicolumn{2}{|c|}{ Contribution Categories } & \multirow{2}{*}{$\begin{array}{l}\text { Author Initials } \\
\text { F.O. }\end{array}$} \\
\hline \multirow{3}{*}{ Category 1} & Concept/Design & \\
\hline & Data acquisition & I.T. \\
\hline & Data analysis/Interpretation & F.O., I.T. \\
\hline \multirow{2}{*}{ Category 2} & Drafting manuscript & F.O. \\
\hline & Critical revision of manuscript & I.T. \\
\hline Category 3 & Final approval and accountability & F.O., I.T. \\
\hline \multirow{2}{*}{ Other } & Technical or material support & F.O. \\
\hline & Supervision & I.T. \\
\hline
\end{tabular}

Ethics Committee Approval: This study was approved by Gaziosmanpasa University Non-Interventional Local Ethics Committee (Date: Nov. 8, 2017, Number: 83116987-433)

Informed Consent: Written informed consent was obtained from the patients.

Peer-review: Externally peer-reviewed.

Conflict of Interest: The authors declared no conflict of interest.

Financial Disclosure: There was no external financing.

\section{REFERENCES}

1. Kwon OY, Park SP. Depression and anxiety in people with epilepsy. J Clin Neurol 2014; 10:175-188.

2. Johnson EK, Jones JE, Seidenberg M, Hermann BP. The relative impact of anxiety, depression, and clinical seizure features on health-related quality of life in epilepsy. Epilepsia 2004; 45:544550 . 
3. Wells A, Cartwright-Hatton S. A short form of the metacognitions questionnaire: properties of the MCQ-30. Behav Res Ther 2004; 42:385-396.

4. Corcoran KM, Segal ZV. Metacognition in depressive and anxiety disorders: current directions. Int J Cogn Ther 2008; 1 : 33-44.

5. Beck AT. Cognitive models of depression. J Cogn Psychother 1987; 1:5-37.

6. Beck JS. Cognitive Therapy: Basics and Beyond. Sahin NH (Translation Editor). Ankara: Turk Psikologlar Dernegi Yayinlari, 2006. (Turkish)

7. Beck JS. Cognitive Therapy: Basics and Beyond. Tari Comert I, Sahin M (Translation Editors). Ankara: Nobel Akademik Yayincilik, 2014. (Turkish)

8. Wilner AN, Sharma BK, Soucy A, Thompson A, Krueger A. Common comorbidities in women and men with epilepsy and the relationship between number of comorbidities and health plan paid costs in 2010. Epilepsy Behav 2014; 32:15-20.

9. Kanner AM. Management of psychiatric and neurological comorbidities in epilepsy. Nat Rev Neurol 2016; 12:106-116.

10. Fisher PL, CookSA, Noble A. Clinical utility of the Metacognitions Questionnaire 30 in people with epilepsy. Epilepsy Behav 2016; 57:185-191.

11. Fisher PL, Reilly J, Noble A. Metacognitive beliefs and illness perceptions are associated with emotional distress in people with epilepsy. Epilepsy Behav 2018; 86:9-14.

12. Beck AT, Ward CH, Mendelson M, Mock J, Erbaugh J. An inventory for measuring depression. Arch Gen Psychiatry 1961; 4:561-571.

13. Hisli N. Study on the validity of the Beck Depression Inventory. Journal of Psychology 1988; 6:118-126. (Turkish)

14. Beck AT, Epstein N, Brown G, Steer RA. An inventory for measuring clinical anxiety: psychometric properties. J Consult Clin Psychol 1988; 56:893-897.

15. Ulusoy M, Sahin NH, Erkmen H. Turkish version of the Beck Anxiety Inventory: psychometric properties. J Cogn Psychother $1988 ; 12: 163-172$.

16. Tosun A, Irak M. Adaptation, validity, and reliability of the Metacognition Questionnaire-30 for the Turkish population, and its relationship to anxiety and obsessive-compulsive symptoms. Turk Psikiyatri Derg 2008; 19:67-80.

17. Hollan SD, Kendall PC. Cognitive self-statements in depression: Development of an Automatic Thoughts Questionnaire. Cognit Ther Res 1980; 4:383-395.
18. Sahin NH, Sahin N. Reliability and validity of Turkish version of the Automatic Thoughts Questionnaire. J Clin Psychol 1992; 48:334-340. Turkish

19. Weissman AN, Beck AT. Development and validation of the Dysfunctional Attitude Scale: A preliminary investigation. Paper presented at the Annual Meeting of the American Educational Research Association, Toronto, Ontario 1978.

20. Sahin NH, Sahin N. Are attitudes that are functional in one culture also functional in another culture? Psychometric properties of the Dysfunctional Attitude Scale. Journal of Psychology 1991; 7:30-40. (Turkish)

21. Yilmaz S, Izci F, Mermi, O, Atmaca M. Metacognitive functions in patients who has [sic] obsessive compulsive disorder and major depressive disorder: a controlled study. Anadolu Psikiyatri Derg 2016; 17:451-458. (Turkish)

22. McGee RE, Sajatovic M, Quarells RC, Johnson EK, Liu H, Spruill TM, et al. Depression and quality of life among African Americans with epilepsy: Findings from the Managing Epilepsy Well (MEW) Network integrated database. Epilepsy Behav 2019; 94:301-306.

23. De Marco AP, Mahoney JJ 3rd, Aduen PA, Langer J, Bajo SD, Broshek DK. The relationship between the Neuro-Quality of Life Depression and Anxiety Measures and the Personality Assessment Inventory in persons with epilepsy. Epilepsy Behav 2017; 70:145-149.

24. Grotte T, Solem S, Vogel PA, Guzey IC, Hansen B, Myers SG. Metacognitions, responsibility, and perfectionism in obsessive-compulsive disorder. Cognit Ther Res 2015; 39:41-50.

25. Boke O, Pazvantoglu O, Babadagi Z, Unverdi E, Ay R, Cetin E, Sahin AR. Metacognitions in panic disorder. Anadolu Psikiyatri Derg 2015; 16:1-6. (Turkish)

26. Zettle RD, Webster BK, Grid SR, Wagener AL, Burdsal CA. Factor structure of the thoughts questionnaire in a clinical sample. Int J Cogn Ther 2013; 6:280-282.

27. Horiuchi S, Aoki S, Takagaki K, Shoji F. Association of perfectionistic and dependent dysfunctional attitudes with subthreshold depression. Psychol Res Behav Manag 2017; 10: 271-275

28. Fonseca A, Canavarro MC. Exploring the paths between dysfunctional attitudes towards motherhood and postpartum depressive symptoms: The moderating role of self-compassion. Clin Psychol Psychother 2018;25:e96-e106.

29. Babayigit Z, Alcalar N, Bahadir G. Investigation of psychopathology and cognitive aspects of binge eating disorder in obese women. Turkiye Klinikleri J Med Sci 2013;33:10771087. 